\title{
RANCANG BANGUN SISTEM INFORMASI INVENTORY FASILITAS MAINTENANCE PADA PT. PLN (PERSERO) TANGERANG
}

\author{
Giandari Maulani ${ }^{1}$ \\ Devi Septiani ${ }^{2}$ \\ Putri Noer Fauziyah Sahara ${ }^{3}$
}

\begin{abstract}
Dosen Sistem Informasi STMIK Raharja ${ }^{1}$, Sarjana S1 (alumni) Sistem Informasi STMIK Raharja ${ }^{2}$, Mahasiswa jurusan Sistem Informasi STMIK Raharja ${ }^{3}$

Jl. Jenderal Sudirman No.40 Modernland Cikokol, Tangerang ${ }^{1,2,3}$

e-mail: giandari@ raharja.info ${ }^{1}$, devi.septiani@ raharja.info ${ }^{2}$, putri.noer@ raharja.info $^{3}$
\end{abstract}

\begin{abstract}
ABSTRAK
PT.PLN (Persero) memiliki banyak cabang di seluruh Indonesia, salah satunya PT.PLN (Persero) yang terletak di JL.Raya Serang km.17 Cikupa Tangerang yang menjadi tempat untuk penelitian ini. PT.PLN (Persero) bergerak dalam bidang penyaluran tenaga listrik untuk didistribusikan kepada masyarakat sekaligus melakukan pemeliharaan peralatan listriknya. Peralatan yang ada digudang perusahaan sering tidak terkontrol jumlah dan penggunaannya karena saat itu tidak adanya sistem yang mengatur keluar masuknya barang, sehingga dalam pencarian atau peminjaman peralatannya membutuhkan waktu yang lama. Inventory gudang merupakan bagian terpenting dalam perusahaan karena didalamnya menampung peralatan yang biasa digunakan untuk kegiatan kerja. Adapun tujuan penelitian ini untuk membantu menyelesaikan permasalahan yang terjadi agar proses kegiatan kerja dapat berjalan dengan baik. Untuk itu perlu adanya rancang bangun sistem informasi terkomputerisasi yang dapat meminimalisir lamanya proses pencarian serta keamanan datanya dapat terjaga. Metodologi yang digunakan dalam penelitian ini, yakni metode pengumpulan data, metode analisa, metode perancangan dan metode pengujian dengan Black Box Testing. Hasil penelitian ini berupa Aplikasi sistem informasi inventory fasilitas maintenance berbasis web yang dirancang bangun dengan menggunakan program berbasis PHP dan MySQL yang cocok untuk menampung seluruh informasi inventory khusus fasilitas maintenance PT.PLN (Persero) Tangerang.
\end{abstract}

Kata kunci: Sistem Informasi, Inventory, fasilitas Maintenance.

\begin{abstract}
PT. PLN (Persero) has many branches across Indonesia, one of the PT. PLN (Persero) located in JL. Raya Serang Tangerang Cikupa. $17 \mathrm{~km}$ which becomes a place for this research. PT. PLN (Persero) engaged in the distribution of electricity to be distributed to the community while doing maintenance of electrical equipment. Existing equipment company digudang is often uncontrolled quantities and their use because the absence of a system set out the influx of goods, so that in searches or loaning equipment takes a long time. Warehouse inventory is the most important part in the company because it accommodates the usual equipment used for work. As for the purpose of this research was to help resolve problems that occur in order for the process to work activities can be run well. For it is need for computerized information systems architecture that can minimize the length of the search process as well as the security of its data can be maintained. The methodology used in this study, namely, data collection methods, analysis method, a method of designing and testing methods with Black Box Testing. The results of this research in the form of the application inventory information system webbased maintenance facility designed to wake up by using PHP and MySQL-based programs are suitable to accommodate all the information a special inventory of facilities maintenance PT . PLN (Persero) Tangerang.
\end{abstract}

Keyword: Information Systems, Inventory, Maintenance facility. 


\section{PENDAHULUAN}

PT. PLN (Persero) merupakan sebuah Badan Usaha Milik Negara yang mengurusi seluruh kebutuhan kelistrikan untuk masyarakat Indonesia. PT. PLN (Persero) Tangerang bergerak dalam bidang pendistribusian listrik khusus untuk masyarakat yang bermukim diwilayah Tangerang. Permasalahan terjadi ketika banyaknya peralatan serta barang-barang di gudang yang masih tidak terkontrol jumlah serta penggunaannya untuk kegiatan apa saja, yang membuat sistem inventorynya tidak terstruktur dan kurang bagus. Saat itu sistem informasi khusus persediaan/inventory untuk fasilitas maintenance pada PT. PLN (Persero) Tangerang masih belum terkomputerisasi/masih manual serta tidak adanya pengaturan keluar masuknya barang. oleh karena itu diperlukanlah sebuah desain/rancang bangun sistem informasi khusus inventory terutama untuk fasilitas maintenance yang dapat mempermudah pengontrolan peralatan-peralatan yang ada secara cepat dan akurat. Setelah dilakukan analisa ditempat penelitian, maka terdapat beberapa rumusan masalahnya, antara lain : 1). Apakah sistem persediaan barang pada PT.PLN (Persero) Tangerang sudah terkelola dengan baik? 2). Apakah sistem yang ada saat ini sudah efektif dan efisien? 3). Apakah dengan adanya sistem informasi inventory fasilitas maintenance pada PT.PLN (Persero) Tangerang dapat meningkatkan kinerja kerja? Pertanyaan-pertanyaan diatas akan ditemukan solusinya pada penelitian ini. Untuk Landasan teori, penelitian ini menjabarkan beberapa definisi, sbb:

\section{Definisi Rancang Bangun}

Rancang bangun adalah menciptakan dan membuat suatu aplikasi ataupun sistem yang belum ada pada suatu instansi atau objek tersebut. ${ }^{[1]}$

\section{Definisi Sistem Informasi}

Sistem informasi adalah suatu sistem yang berhubungan dengan pengumpulan, penyimpanan dan pemrosesan data, baik yang dilakukan secara manual,maupun berbantuan computer, untuk menghasilkan informasi yang sangat berguna bagi proses pengambilan keputusan. ${ }^{[2]}$

\section{Definisi Inventory}

Inventory adalah Sejumlah barang-barang yang disediakan untuk memenuhi permintaan dari pelanggan. ${ }^{[3]}$

\section{Definisi Fasilitas}

Fasilitas merupakan sarana baik berupa barang maupun jasa yang diberikan oleh perusahaan kepada pelanggan guna mewujudkan kepuasan pelanggannya. ${ }^{[4]}$

\section{Definisi Maintenance}

Maintenance adalah suatu kombinasi dari berbagi tindakan yang dilakukan untuk menjaga suatu barang atau memperbaikinya, sampai pada suatu kondisi yang bisa diterima. ${ }^{[5]}$

\section{Definisi Unified Modeling Languange (UML)}

UML merupakan sintesis dari tiga metode analisis dan perancangan berbasis objek serta ditambah dengan keunggulan metode-metode berorientasi objek lainnya (fushion, shlaermellon, coad-yourdom) yang juga disintesiskan dalam UML menawarkan pendekatan yang cukup baik yang sudah digunakan diindustri perangkat lunak. ${ }^{[6]}$ 


\section{Definisi Black Box}

Black Box Testing berfokus pada spesifikasi fungsional dari perangkat lunak. Tester dapat mendefinisikan kumpulan kondisi input dan melakukan pengetesan pada spesifikasi fungsional program. ${ }^{[7]}$

Studi literatur merupakan pengumpulan data-data dan informasi dengan cara menggali pengetahuan atau ilmu dari sumber-sumber seperti buku, karya-karya tulis, diktat catatan kuliah dan beberapa sumber-sumber lainnya yang ada kaitannya dengan objek penelitian. ${ }^{[8]}$ Literatur pada penelitian ini sebagai berikut :

1. Penelitian yang dilakukan oleh Karlena Indriani dan Sudarmadi yang berjudul "SISTEM INFORMASI INVENTORY ALAT TULIS KANTOR/ATK MENGGUNAKAN METODE WATERFALL". Sistem pengolahan ATK (alat-alat tulis kantor) di Otoritas Jasa Keuangan/OJK sekarang ini masih dilaksanakan secara manual, sehingga sering terjadinya kesalahan informasi. ${ }^{[9]}$

2. Penelitian yang dilakuan oleh Sriadhi yang berjudul "RANCANG BANGUN SISTEM INFORMASI INVENTARIS BERBASIS MULTIMEDIA AKSES ONLINE". Tujuan penelitian ini yakni membangun sistem informasi inventaris berbasis multimedia yang dapat memenuhi kebutuhan spesifik dari user/pengguna,menerapkan metode SLDC. ${ }^{[10]}$

3. Penelitian oleh Zefriyenni dan Budi Santoso yang berjudul "SISTEM INFORMASI PENJUALAN SERTA PENGENDALIAN PERSEDIAAN BARANG MENGGUNAKAN METODE EOQ (ECONOMIC ORDER QUANTITY) MENGGUNAKAN BAHASA PEMROGRAMAN JAVA DAN DATABASE MYSQL PADA TOKO KANSA ELPIJI". Proses pengolahan data yang masih manual membuat laporan penjualan sering mengalami keterlambatan. ${ }^{[11]}$

4. Penelitian berikutnya oleh Haryani yang berjudul "SISTEM INFORMASI PENGELOLAAN INVENTORY FIXED PADA PT.ARK DAN TRANSPORT". Adapun penggunaan program aplikasi yang dibuat untuk penghitungan pengadaan aset, manajemen aset, penyusutan aset dan lelang aset ataupun menghapus aset perusahaan. ${ }^{[12]}$

5. Penelitian yang dilakukan oleh William Mwangi dan Miriam Thogori Nyambura yang berjudul "THE ROLE OF INVENTORY MANAGEMENT ON PERFORMANCE OF FOOD PROCESSING COMPANIES : A CASE STUDY OF CROWNFOODS LIMITED KENYA". Penelitian ini menggunakan alat instrumentasi berupa Quesioner untuk mengumpulkan data-data primer. Data diringkas dan dikategorikan menurut tema umum serta penggunaan statistik deskriptif untuk menganalisis data-datanya. ${ }^{[13]}$

Adapun perbedaan Literature Review yang dijelaskan diatas dengan penelitian ini, yakni : 1)Sistem sebelumnya masih manual dan akan dibuatkan sistem informasi yang baru berbasiskan Website. 2)Penelitian ini akan menghasilkan data pengelolaan inventory yang update. 3)Hasil penelitian ini dapat menghemat waktu,memudahkan pekerjaan serta dapat mengetahui informasi data inventory secara cepat dan akurat.

\section{METODOLOGI PENELITIAN}

Dalam penelitian ini proses pengumpulan datanya menggunakan metode sebagai berikut :

1) Metode Pengumpulan Data, yang terdiri dari : a) Observasi (Observation); dalam metode ini langsung mendatangi dan meneliti PT.PLN (Persero) Tangerang untuk mengetahui secara langsung apasaja yang menjadi kendala dan permasalahannya kemudian teliti dan dianalisa terutama untuk sistem yang ada/sedang berjalan. b) Wawancara (Interview); dalam metode ini dilakukan beberapa tanya jawab yang dilakukan secara langsung dengan pihak yang berhubungan dengan objek penelitian yang berhubungan dengan sistem inventory yaitu wawancara kepada Bpk. Edi Sastra. c) Studi Pustaka (Literature Review); 
suatu metode untuk memperoleh sejumlah informasi dengan cara mempelajari buku-buku serta literatur dari berbagai sumber guna melengkapi informasi yang dibutuhkan.

2) Metode Analisa : Metode ini untuk mengetahui permasalahan yang ada di PT.PLN (Persero) Tangerang dan mendapatkan data yang diperlukan dalam penyusunan penelitian.

3) Metode Perancangan : Pada metode ini, penggambaran metode yang berjalan dan rancangan yang diusulkan menggunakan diagram UML (Unified Modeling Language). Untuk pembuatan Database dan programnya disesuaikan dengan kebutuhan Stakeholder dalam tahapan elisitasi dan untuk bahasa pemogramannya menggunakan bahasa $P H P$.

4) Metode Pengujian (Testing) : Metode ini menggunakan Black Box Testing untuk menunjukkan fungsi-fungsi yang ada didalam sebuah perangkat lunak.

\section{PEMBAHASAN \& PEMECAHAN MASALAH}

\section{Rancangan Sistem}

Rancangan sistem untuk penelitian di PT. PLN (Persero) Tangerang ini digambarkan dengan diagram UML (Unified Modeling Language) yang merupakan bahasa permodelan untuk software yang berorientasi objek, seperti dibawah ini :

\section{A. Diagram Usecase}

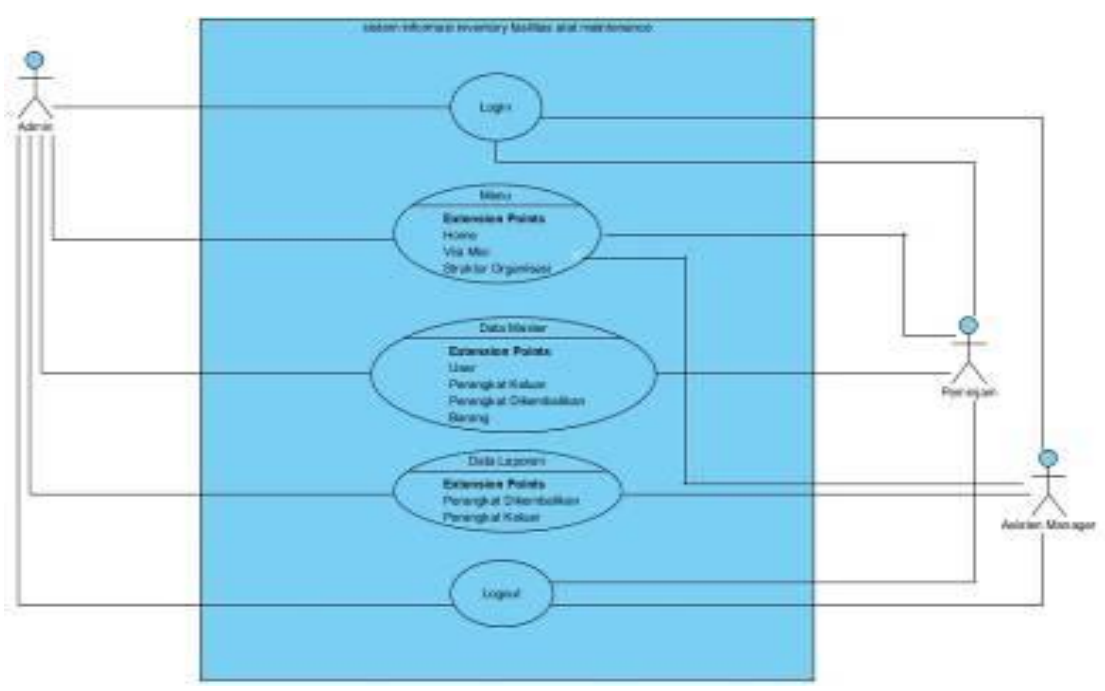

Gambar 1. Use case diagram untuk Inventory Fasilitas Maintenance di Gudang

Berdasarkan gambar 1. Use case diagram sistem, terdapat: 1 (Satu) sistem yang mencakup seluruh kegiatan sistem inventory fasilitas alat maintenance, ada juga 3 (tiga) actor yang melakukan berbagai kegiatan, yaitu admin, asisten manager dan peminjam dan 5 (lima) Usecase kegiatan yang dilakukan oleh actor. 


\section{B. Diagram Sequence}

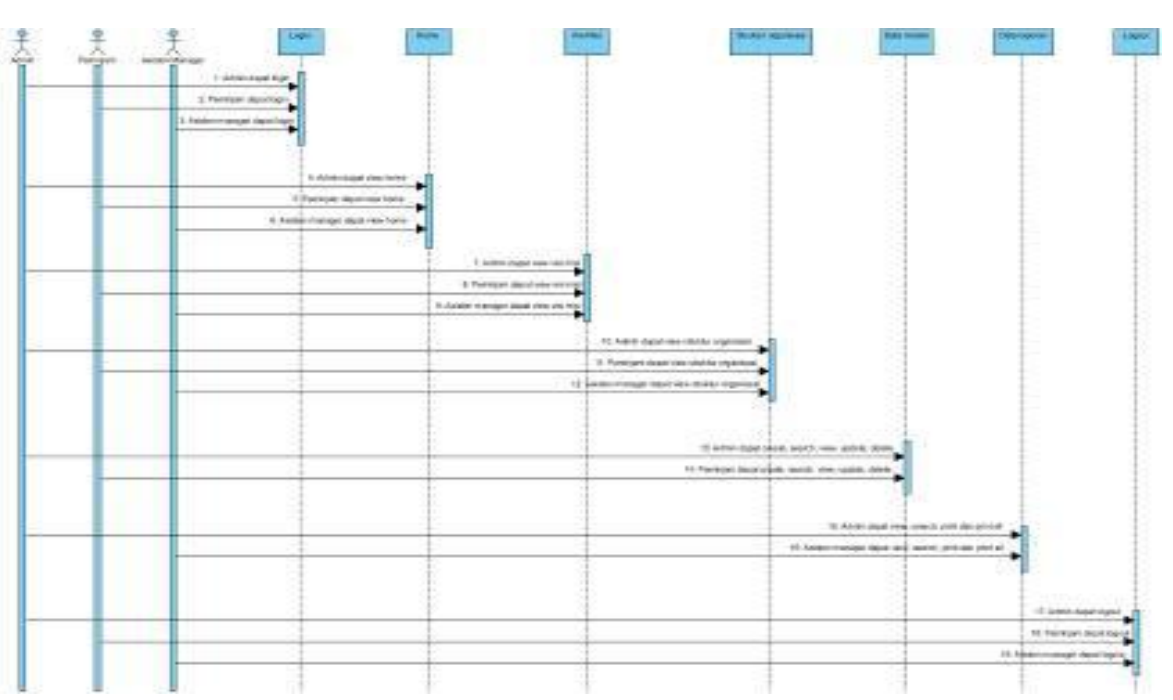

Gambar 2. Sequence diagram Inventory Fasilitas Alat Maintenance di Gudang

Gambar 2 diatas, pada Sequence diagramnya terdapat: 3 (tiga) aktor yang melaksanakan yaitu admin, peminjam dan asisten manager yang melakukan beberapa kegiatan, 7 (tujuh) lifeline, yaitu login, menu home, menu visi misi, menu struktur, menu data master, menu data laporan, logout dan 19 (sembilan belas) message yang menjadi alat komunikasi antar objekobjek yang dapat mencakup informasi tentang beberapa aktifitas yang terjadi.

\section{Uji Validitas}

Untuk uji validitas pada penelitian kali ini dengan menggunakan Blackbox Testing. Blackbox Testing merupakan metode proses pengujian perangkat lunak yang hanya memfokuskan kepada keperluan software, oleh sebab itu Blackbox Testing ini dapat mengetahui dan dapat memastikan dengan benar apakah pemasukan data diterima dan keluaran data-data yang dihasilkan agar sesuai dengan yang diharapkan.

Tabel 1. Blackbox Testing Menu Login

\begin{tabular}{|c|c|c|c|c|c|}
\hline No. & $\begin{array}{l}\text { Skenario } \\
\text { Pengujian }\end{array}$ & Test Case & $\begin{array}{l}\text { Hasil yang } \\
\text { diharapkan }\end{array}$ & Hasil Pengujian & Ket. \\
\hline 1. & $\begin{array}{l}\text { Mengisikan dengan } \\
\text { data salah lalu } \\
\text { langsung pilih } \\
\text { "login". }\end{array}$ & 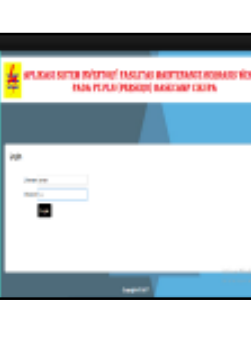 & $\begin{array}{l}\text { Sistem akan } \\
\text { membatalkan } \\
\text { akses login dan } \\
\text { menampilkan } \\
\text { pesan "Incorrect } \\
\text { username or } \\
\text { password". }\end{array}$ & " & Valid \\
\hline 2. & $\begin{array}{l}\text { Mengisikan } \\
\text { username dan } \\
\text { password yang } \\
\text { benar, lalu langsung } \\
\text { pilih "Login". }\end{array}$ & & $\begin{array}{l}\text { Sistem segera } \\
\text { merespon dan } \\
\text { mengecek user } \\
\text { name dan pass } \\
\text { word, jika benar } \\
\text { maka dpt masuk. }\end{array}$ & Hitivic & Valid \\
\hline
\end{tabular}




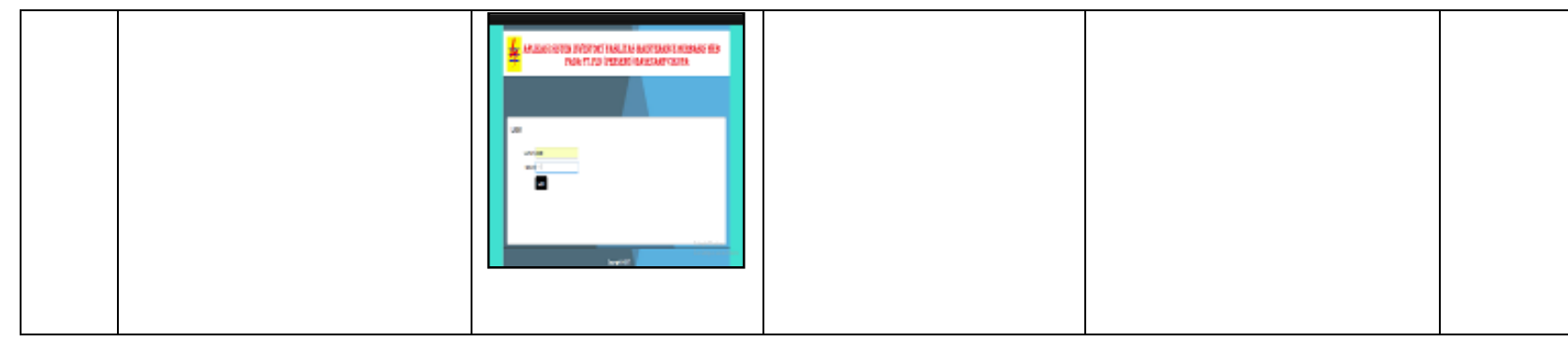

Tabel 2. Blackbox Testing Input User

\begin{tabular}{|c|c|c|c|c|c|}
\hline No. & $\begin{array}{c}\text { Skenario } \\
\text { Pengujian }\end{array}$ & Test Case & $\begin{array}{l}\text { Hasil yang } \\
\text { diharapkan }\end{array}$ & Hasil Pengujian & Ket. \\
\hline 1. & $\begin{array}{l}\text { Klik menu "data } \\
\text { master" lalu klik } \\
\text { "data user" dan } \\
\text { "create" untuk } \\
\text { membuat akun user } \\
\text { baru. }\end{array}$ & 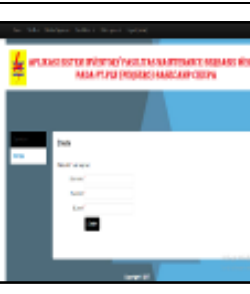 & $\begin{array}{l}\text { Sistem akan } \\
\text { menampilkan } \\
\text { halaman data } \\
\text { user. }\end{array}$ & $=$ & Valid \\
\hline 2. & $\begin{array}{l}\text { Klik menu "data } \\
\text { master" lalu klik } \\
\text { "data user" dan } \\
\text { "update" untuk } \\
\text { memperbaharui } \\
\text { data user. }\end{array}$ & 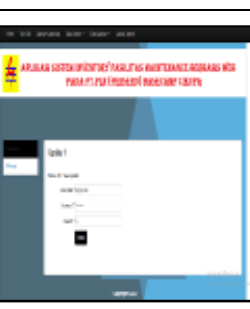 & $\begin{array}{l}\text { Sistem akan } \\
\text { menampilkan } \\
\text { halaman data } \\
\text { user. }\end{array}$ & 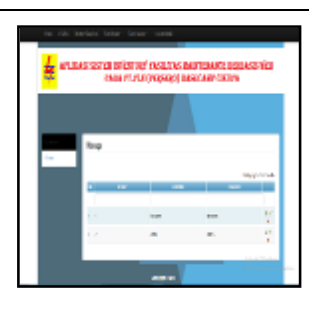 & Valid \\
\hline
\end{tabular}

Tabel 3. Blackbox Testing Perangkat Keluar

\begin{tabular}{|c|c|c|c|c|c|}
\hline No. & $\begin{array}{c}\text { Skenario } \\
\text { Pengujian }\end{array}$ & Test Case & $\begin{array}{c}\text { Hasil yang } \\
\text { diharapkan }\end{array}$ & Hasil Pengujian & Ket. \\
\hline 1. & $\begin{array}{l}\text { Klik menu "data } \\
\text { master" lalu klik } \\
\text { "perangkat keluar" } \\
\text { dan "create" untuk } \\
\text { mengisi data } \\
\text { perangkat keluar. }\end{array}$ & $=$ & $\begin{array}{l}\text { Sistem akan } \\
\text { menuju ke } \\
\text { halaman } \\
\text { perangkat keluar. }\end{array}$ & & Valid \\
\hline 2. & $\begin{array}{l}\text { Klik menu "data } \\
\text { master" lalu klik } \\
\text { "perangkat keluar" } \\
\text { dan "update" untuk } \\
\text { mengedit data } \\
\text { perangkat keluar. }\end{array}$ & 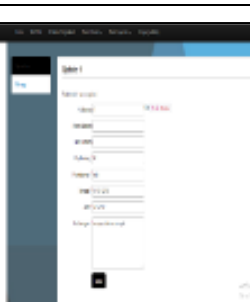 & $\begin{array}{l}\text { Sistem akan } \\
\text { membawa ke } \\
\text { halaman } \\
\text { perangkat keluar. }\end{array}$ & 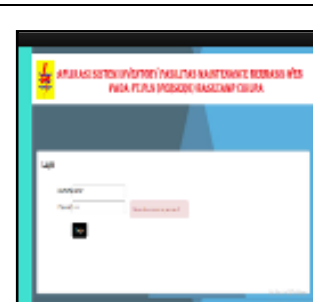 & Valid \\
\hline
\end{tabular}


Tabel 4. Blackbox Testing Perangkat Dikembalikan

\begin{tabular}{|c|c|c|c|c|c|}
\hline No. & $\begin{array}{c}\text { Skenario } \\
\text { Pengujian }\end{array}$ & Test Case & $\begin{array}{c}\text { Hasil yang } \\
\text { diharapkan }\end{array}$ & Hasil Pengujian & Ket. \\
\hline 1. & $\begin{array}{l}\text { Klik menu } \\
\text { "data master" } \\
\text { lalu klik } \\
\text { "perangkat } \\
\text { dikembalikan" } \\
\text { dan "create" } \\
\text { untuk mengisi } \\
\text { data perangkat } \\
\text { dikembalikan. }\end{array}$ & 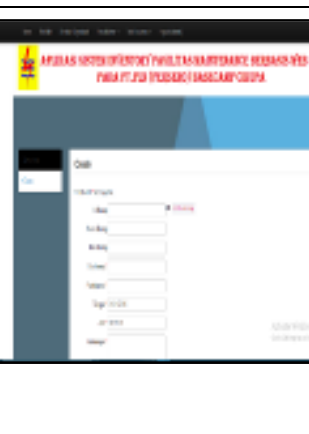 & $\begin{array}{l}\text { Sistem akan } \\
\text { memunculkan } \\
\text { halaman } \\
\text { perangkat } \\
\text { dikembalikan. }\end{array}$ & 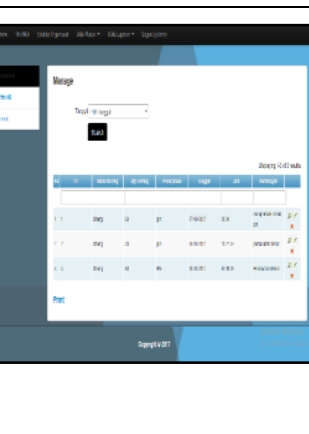 & Valid \\
\hline 2. & $\begin{array}{l}\text { Klik menu } \\
\text { "data master" } \\
\text { lalu klik } \\
\text { "perangkat } \\
\text { dikembalikan" } \\
\text { dan "update" } \\
\text { untuk } \\
\text { mengperbaharu } \\
\text { i data } \\
\text { perangkat } \\
\text { dikembalikan. }\end{array}$ & 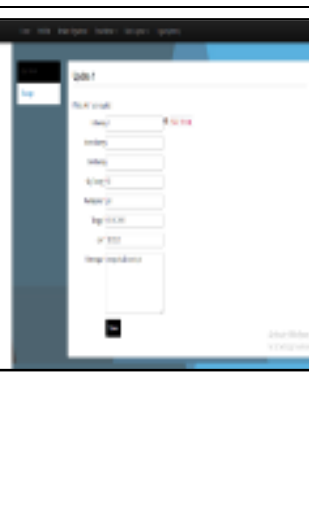 & $\begin{array}{l}\text { Sistem akan } \\
\text { melanjutkan ke } \\
\text { halaman } \\
\text { perangkat } \\
\text { dikembalikan. }\end{array}$ & $\frac{m}{m-\infty}$ & Valid \\
\hline
\end{tabular}

Tabel 5. Blackbox Testing Data Barang

\begin{tabular}{|c|c|c|c|c|c|}
\hline No. & $\begin{array}{c}\text { Skenario } \\
\text { Pengujian }\end{array}$ & Test Case & $\begin{array}{c}\text { Hasil yang } \\
\text { diharapkan }\end{array}$ & Hasil Pengujian & Ket. \\
\hline 1. & $\begin{array}{l}\text { Klik menu } \\
\text { "data master" } \\
\text { lalu klik } \\
\text { "barang" dan } \\
\text { "create" untuk } \\
\text { mengisi data } \\
\text { barang. }\end{array}$ & 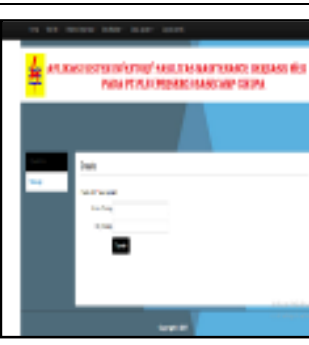 & $\begin{array}{l}\text { Sistem akan } \\
\text { mengarahkan ke } \\
\text { halaman data } \\
\text { barang. }\end{array}$ & $=$ & Valid \\
\hline 2. & $\begin{array}{l}\text { Klik "data } \\
\text { master" lalu } \\
\text { klik "barang", } \\
\text { dan "update" } \\
\text { data barang. }\end{array}$ & 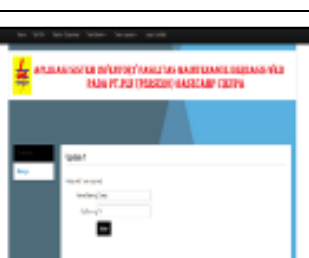 & $\begin{array}{l}\text { Sistem akan } \\
\text { melanjutkan ke } \\
\text { halaman data } \\
\text { barang. }\end{array}$ & 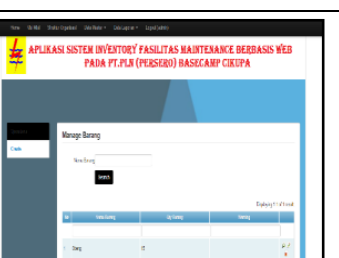 & Valid \\
\hline
\end{tabular}

\section{IMPLEMENTASI}

Dibawah ini adalah beberapa hasil implementasi interface tampilan setiap menu berdasarkan Sistem Informasi inventory fasilitas maintenance yang berbasis Website: 


\section{Tampilan Halaman Login}

Tampilan menu login muncul setelah membukanya di web browser. User perlu menginput data username dan password terlebih dahulu. Sistem ini dipergunakan oleh admin.

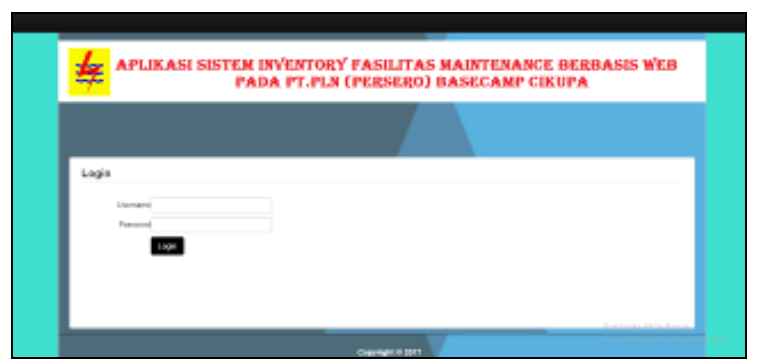

Gambar 3. Halaman Login

\section{Tampilan Menu Utama Home}

Tampilan menu utama home muncul setelah admin berhasil melakukan login sistem. Menu utama home merupakan tampilan awal saat sistem telah login.

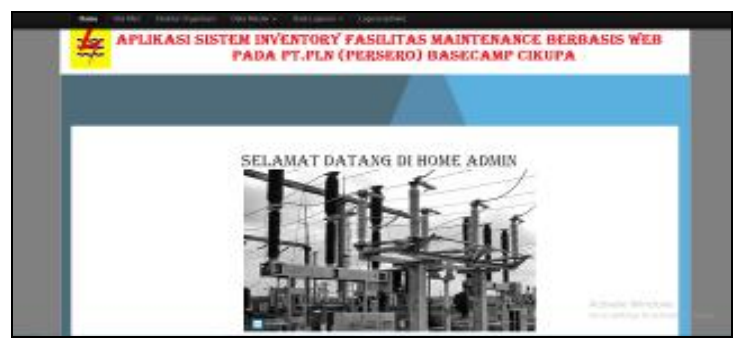

Gambar 4. Menu Utama Home

\section{Tampilan Menu Visi dan Misi}

Tampilan menu visi dan misi muncul jika telah berhasil login sebagai admin. Tampilan menu visi dan misi merupakan visi misi yang sudah ada di PT.PLN (Persero) Tangerang.

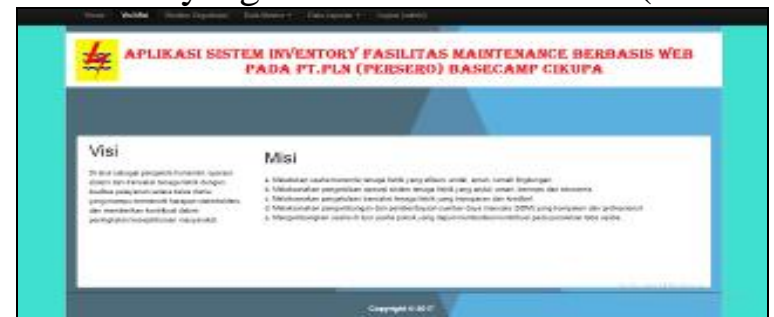

Gambar 5. Menu Visi dan Misi

\section{Tampilan Menu User}

Tampilan menu user muncul setelah admin berhasil melakukan login. Menu ini dapat berfungsi dalam hal view, update, delete dan search username.

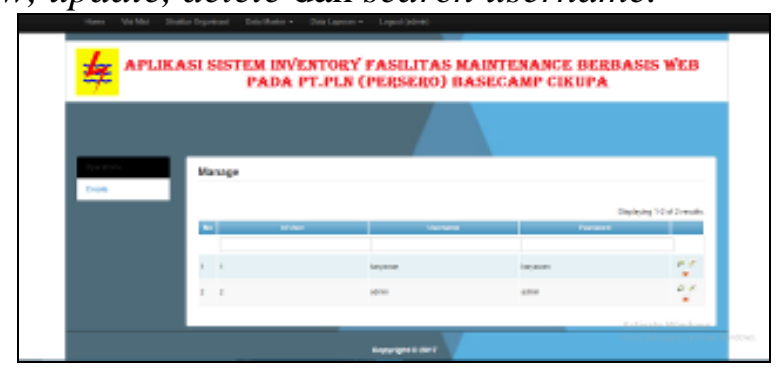

Gambar 6. Menu User 


\section{Tampilan Menu Create User}

Tampilan ini muncul setelah berhasil meakukan login dan masuk ke tampilan menu user. Menu ini dapat berfungsi saat akan membuat user baru dengan menginput data username dan password yang baru.

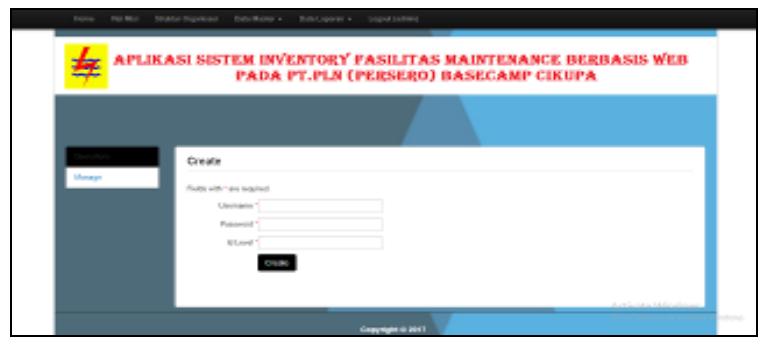

Gambar 7. Menu Create User

\section{Tampilan Menu Perangkat Keluar}

Tampilan ini muncul saat telah berhasil melakukan login akun. Menu ini juga dapat berfungsi untuk view, update, delete dan search perangkat keluar/ dipinjam.

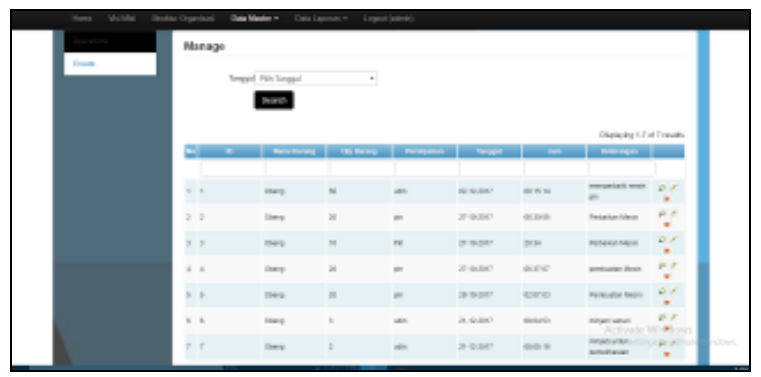

Gambar 8. Menu Perangkat Keluar

\section{Tampilan Menu Perangkat Dikembalikan}

Menu ini akan keluar setelah berhasil melakukan login. Menu perangkat dikembalikan berfungsi untuk view, update, delete dan search perangkat dikembalikan.

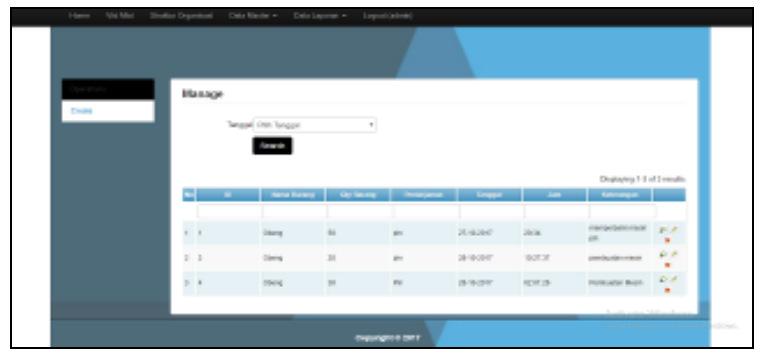

Gambar 9. Menu Perangkat Dikembalikan

\section{Menu Barang}

Tampilan ini muncul saat telah berhasil melakukan login. Menu barang berfungsi untuk view, update, delete dan search barang. 


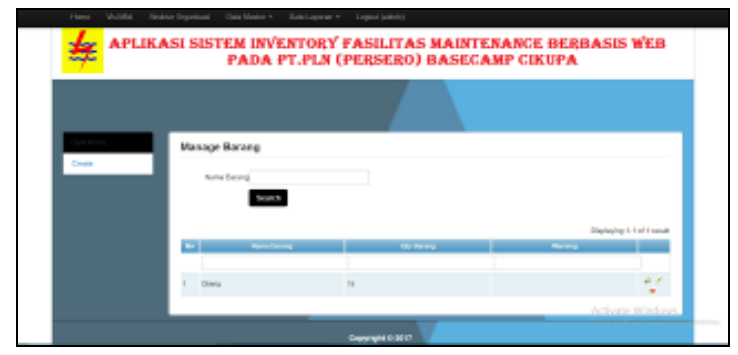

Gambar 10. Menu Barang

\section{Menu Data Laporan Perangkat Dikembalikan}

Tampilan ini muncul setelah berhasil melakukan login akun. Menu ini juga dapat berfungsi sebagai view, update, delete dan search laporan perangkat dikembalikan.

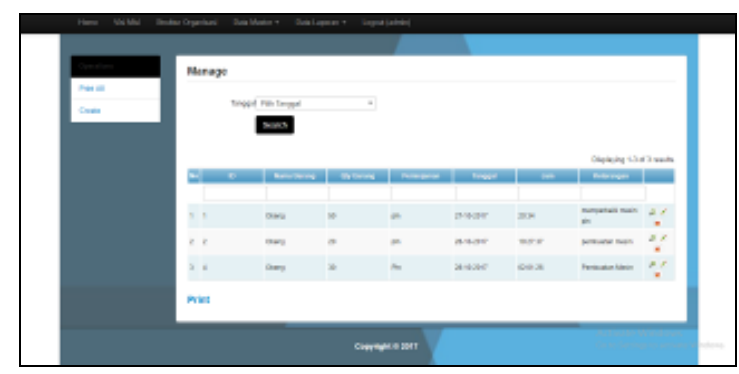

Gambar 11. Laporan Perangkat Dikembalikan

\section{Menu Print All Laporan Perangkat Dikembalikan}

Tampilan ini muncul setelah berhasil melakukan login. Menu ini akan berfungsi dalam hal print semua laporan perangkat dikembalikan.

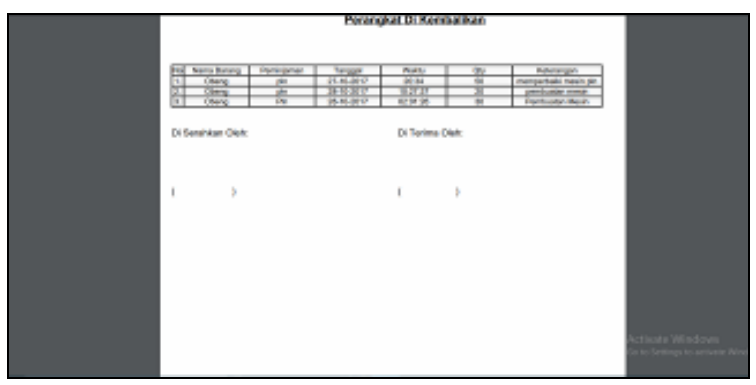

Gambar 12. Menu Print All Laporan Perangkat Dikembalikan

\section{Menu Laporan Perangkat Keluar}

Tampilan ini akan muncul jika berhasil login. Menu ini dapat pula berfungsi untuk view, update, delete dan search laporan perangkat keluar.

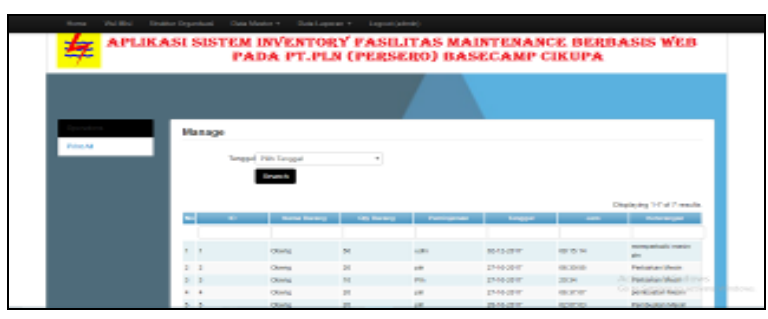

Gambar 13. Laporan Perangkat Keluar 


\section{Menu Print All Laporan Perangkat Keluar}

Tampilan ini muncul setelah berhasil melakukan login. Menu ini berfungsi untuk print semua laporan perangkat keluar.

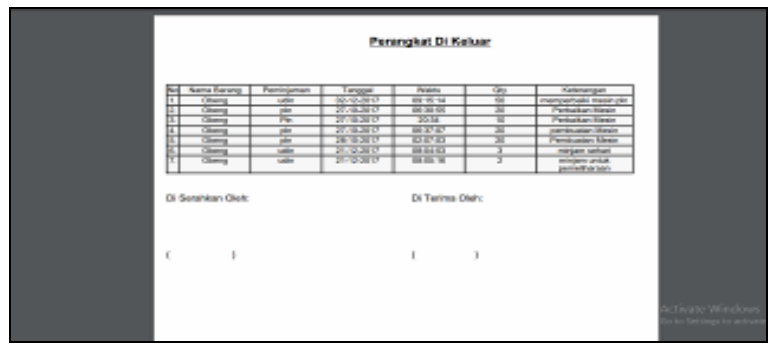

Gambar 14. Menu Print All Laporan Perangkat Keluar

\section{KESIMPULAN}

Untuk kesimpulan yang dapat diberikan dari hasil penelitian ini, antara lain : 1) Sistem persediaan barang pada PT.PLN (Persero) Tangerang pada saat itu belum terkelola dengan baik karena proses peminjaman barang, pengembalian dan data-data barang inventory belum terhimpun dalam satu basis data/database terkomputerisasi. 2) Sistem yang ada saat itu belum efektif dan efisien karena sistemnya masih dikerjakan secara manual sehingga memerlukan banyak waktu untuk penyelesaian pekerjaannya. 3) Dengan adanya sistem informasi inventory fasilitas maintenance pada PT.PLN (Persero) Tangerang yang dibuat menggunakan program PHP dan MySQL ini ternyata dapat memudahkan pihak gudang maupun peminjam barang untuk mendapatkan berbagai informasi mengenai inventory barang di gudang dengan cepat karena data-data barang terhimpun dalam satu database, sehingga dapat meminimalisir waktu dan karena hal ini kinerja kerja dapat terus meningkat.

\section{SARAN}

Adapun Saran yang dapat diberikan antara lain: Disarankan untuk dapat memaksimalkan sistem informasi inventory fasilitas maintenance yang telah dirancang ini dengan melakukan perawatan sistem atau mengupgrade sistem secara berkala. Disarankan perlu adanya pelatihan-pelatihan kepada admin dan pemegang hak akses lainnya,terutama untuk cara menggunakan sistem informasi inventory fasilitas maintenance yang terbaru ini agar lebih dimengerti sehingga pengerjaannya dapat lebih efektif dan efisien. Disarankan untuk dapat melakukan pengembangan pada sistem informasi inventory fasilitas maintenance ini agar menjadi sempurna, tetap uptodate dan tetap sesuai kebutuhan inventory barang yang juga semakin berkembang.

\section{DAFTAR PUSTAKA}

[1] Muarie,Muhamad Son. 2015. Rancang Bangun Sistem Ujian Online Pada SMP Negeri 8 Sekayu. TIPS-Jurnal Teknik Informatika Politeknik Sekayu Vol.II, No.1, Maret 2015.

[2] Wahyudiono,Sugeng \& F.A.Anindito. 2015. Sistem Informasi Berbasis Web Otacatic Yogyakarta. TRANSFORMASI-Jurnal Informasi \& Pengembangan Iptek Vol.11,No.1.

[3] Rosyidhana,Akbar. 2014. Sistem Informasi Inventory dan Penjualan Berbasis Web di Toko Bangunan Enggal Jaya Klaten. Tugas Akhir. Yogyakarta: Gadjah Mada. 
[4] Susanti,Desi. 2017. Pengaruh Faktor Kepercayaan, Kualitas Layanan dan Fasilitas Terhdap Kepuasan Pelanggan Kereta Api. Jurnal Ilmu dan Riset Manajemen Vol.6, No.5, Mei 2017.

[5] Simanungkalit,Patardo, R.Yasra \& B.W.Widodo. 2016. Perencanaan Sistem Perawatan Alat Angkat Kapasitas 5 Ton dengan Metode Preventive Maintenance, Jurnal PROFISIENSI Vol.4, No.1, Juni 2016.

[6] Fridayanthie, Eka Wulansari. 2015. Perancangan Sistem Informasi Penjualan Peralatan Hiking Berbasis Desktop Pada Toko Cimone Outdoor Tangerang. Jurnal Khatulistiwa Informatika, Vol.3, No.2 Desember 2015.

[7] Mustaqbal, M. Sidi. Roeri Fajri Firdaus dan Hendra Rahmadi. 2015. Pengujian Aplikasi Menggunakan Black Box Testing Boundary Value Analysis. Bandung: Jurnal Ilmiah Teknologi Informasi Terapan. Volume 1, No 3, 10 Agustus 2015.

[8] Dewi, Z.A.Trisna, C.Ahmad \& I.G.Suardika. 2015. Dashboard Executive Information System pada Banjar Berbasis Web. JOSINFO-Jurnal Online Sistem Informasi. Vol.1, No.1.

[9] Indriani, Karlena \& Sudarmandi. 2015. Sistem Informasi Inventory Alat Tulis Kantor (ATK) Menggunakan Metode Waterfall. Jakarta: Jurnal Techno Nusa Mandiri. Vol. XII No.1, Maret 2015.

[10] Sriadhi. 2016. Rancang Bangun Sistem Informasi Inventaris Berbasis Multimedia Akses Online. Universitas Negri Medan: Jurnal Sistem Informasi (JSI). Vol.8, No.2, Oktober 2016.

[11] Zefriyenni \& B.Santoso. 2015. Sistem Informasi Penjualan dan Pengendalian Persediaan Barang Menggunakan Metode Economic Order Quantity (EOQ) Menggunakan Bahasa Pemrograman Java dan Database MySQL Pada Toko Kansa Elpiji. Jurnal KOMTEKINFO Fakultas Ilmu Komputer. Vol.2, No.1, Maret 2013.

[12] Haryani. 2017. Sistem Informasi Pengelolaan Inventory Fixed Asset Pada PT. ARK Logistics dan Transport. Jakarta: Jurnal Ekonomi, Sains dan Manajemen. Vol.XV, No.2, September 2017.

[13] Mwangi,William \& M.T.Nyambura. 2015. The Role Of Inventory Management on Performance of Food Processing Companies: A Case Study Of Crown Foods Limited Kenya. European Journal Of Business and Social Sciences, Vol.4, No.04, Juli 2015 . 